University of Wollongong

Research Online

Australian Institute for Innovative Materials -

Papers

Australian Institute for Innovative Materials

$1-1-2017$

\title{
Unlocking the potential of amorphous red phosphorus films as a long-term stable negative electrode for lithium batteries
}

Chandrasekar Mayandi Subramaniyam

University of Wollongong, University of Texas at Austin, cms989@uowmail.edu.au

Zhixin Tai

University of Wollongong, zt525@uowmail.edu.au

Nasir Mahmood

University of Wollongong, nmahmood@uow.edu.au

Dan Zhang

University of Wollongong,, dz966@uowmail.edu.au

Hua-Kun Liu

University of Wollongong, hua@uow.edu.au

See next page for additional authors

Follow this and additional works at: https://ro.uow.edu.au/aiimpapers

Part of the Engineering Commons, and the Physical Sciences and Mathematics Commons

Research Online is the open access institutional repository for the University of Wollongong. For further information contact the UOW Library: research-pubs@uow.edu.au 


\title{
Unlocking the potential of amorphous red phosphorus films as a long-term stable negative electrode for lithium batteries
}

\author{
Abstract \\ Amorphous red phosphorus films (NS-RP) synthesized by a high energy sonication technique delivered a \\ reversible capacity of $2137 \mathrm{~mA} \mathrm{~h} \mathrm{g-1} \mathrm{when} \mathrm{used} \mathrm{as} \mathrm{a} \mathrm{sole} \mathrm{active} \mathrm{lithium} \mathrm{battery} \mathrm{anode.} \mathrm{After}$ \\ incorporation of reduced graphene oxide in NS-RP, the hybrid delivered a reversible capacity of $706 \mathrm{~mA} \mathrm{~h}$ \\ $\mathrm{g}-1$, even after 200 cycles. \\ Disciplines \\ Engineering | Physical Sciences and Mathematics

\section{Publication Details} \\ Subramaniyam, C. M., Tai, Z., Mahmood, N., Zhang, D., Liu, H. Kun., Goodenough, J. B. \& Dou, S. Xue. \\ (2017). Unlocking the potential of amorphous red phosphorus films as a long-term stable negative \\ electrode for lithium batteries. Journal of Materials Chemistry A, 5 (5), 1925-1929.

\section{Authors} \\ Chandrasekar Mayandi Subramaniyam, Zhixin Tai, Nasir Mahmood, Dan Zhang, Hua-Kun Liu, John \\ Goodenough, and Shi Xue Dou
}




\section{Supporting Information}

\section{Unlocking the Potential of Amorphous Red Phosphorus Films as Long-term Stable} Negative Electrode for the Lithium Battery

Chandrasekar M Subramaniyam, ${ }^{\#,}$ Zhixin Tai ${ }^{\#}$, Nasir Mahmood $^{\#}$, Dan Zhang ${ }^{\#}$, Hua Kun

$$
\text { Liu }^{\#, *} \text {, John B Goodenough }{ }^{\S} \text {, Shi Xue Dou }{ }^{\#}
$$

\# Institute for Superconducting and Electronic Materials, Australian Institute of Innovative Materials, Innovation Campus, University of Wollongong, North Wollongong, NSW 2500 Australia

$\S$ Texas Materials Institute, Department of Mechanical Engineering, 204 E. Dean Keeton Street, C2200, University of Texas Austin, Texas 78712 USA

*corresponding author's Email ID: $\underline{\text { hua@uow.edu.au }}$

\section{Experimental details}

All chemicals used were of laboratory grade, purchased from Sigma Aldrich, and used without any further treatment.

\section{Preparation of nanostructured red phosphorus (NS-RP)}

NS-RP was prepared from commercial RP by high-energy ultrasonication with an ultrasonic processors (Model: VC505-VC750, Sonics \& Materials INC, USA). In a typical synthesis, $1 \mathrm{~g}$ of red phosphorus was dispersed in $20 \mathrm{ml}$ distilled water. This solution was then subjected to high-energy sonication for $20 \mathrm{~h}$ in an ice-cooled water bath at an amplitude of 35 with $2 \mathrm{~s}$ pulse time for each on and off pulse. The temperature of the solution was maintained at $<25{ }^{\circ} \mathrm{C}$ by the constant addition of ice cubes into the surrounding water bath. The as-obtained solution was then frozen in a liquid-nitrogen bath and subjected to freeze-drying at $-55^{\circ} \mathrm{C}$ for 3 days. The product was labelled as NS-RP for further analysis. 


\section{Preparation of NS-RP-rGO hybrid}

Three different RP - reduced-graphene-oxide (rGO) hybrids containing 10, 20, and 30 wt.\% rGO were prepared. Appropriate quantities of NS-RP and rGO were put into $20 \mathrm{ml} \mathrm{DD} \mathrm{H}_{2} \mathrm{O}$ and subjected to ultrasonication for $3 \mathrm{~h}$ at an amplitude of 35 with $2 \mathrm{~s}$ pulse time for each on and off pulse. The obtained precursor was freeze-dried at $-55^{\circ} \mathrm{C}$ for 3 days and labelled as NSRP@rGO-10, NS-RP@rGO-20, and NS-RP@rGO-30, respectively.

\section{Material characterizations}

All samples were subjected to physical and electrochemical characterizations. Phase purities were determined by $\mathrm{X}$ ray diffraction (XRD; GBC MMA) with $\mathrm{Cu} \mathrm{K}_{\alpha}$ irradiation at $1 \%$ min scan rate and $0.02^{\circ}$ step size. Morphologies and their compositions were analysed by fieldemission-gun-scanning electron microscopy (FEGSEM, JOEL) operated at $5 \mathrm{~V}$ and $10 \mu \mathrm{A}$, while particle sizes and particle size distributions were determined by transmission electron microscopy (TEM, JOEL JEM 2010) operated at $200 \mathrm{kV}$ with a resolution of $10 \AA$ and processed with Gatan Micrograph software and nanosheet's depth profile was determined using atomic forced microscopy (AFM, Asylum Research MFP-3D Scanning probe microscopy, SPM). The structures and compositions were also analysed by Raman spectroscopy. X ray photoelectron spectroscopy (XPS) was used to determine the surface composition and the valence states of the respective elements. Nitrogen adsorption-desorption studies were performed with a Quantachrome (iQ-MP) for Brunauer-Emmett-Teller (BET) surface-area analysis.

\section{Electrochemical Characterization}

All samples were tested in a classical CR 2032 coin cell in a two-electrode system against $\mathrm{Li}^{+} / \mathrm{Li}^{\circ}$. A slurry containing an 8:1:1 wt. ratio of active material (NS-RP) to carbon Super P (as conducting agent) to polyvinylidene fluoride (PVDF as binder) was prepared with N-methyl2-pyrrolidone (NMP), as blending solvent in a planetary mixer. Electrodes were prepared from 
the NS-RP@rGO hybrid composites in a weight ratio of 7:1.5:1.5 with carboxymethyl cellulose $(\mathrm{CMC})$ as binder and Super P carbon with DD water as solvent. The obtained slurry was tape cast over copper foil with a doctor blade $50 \mu \mathrm{m}$ in thickness and vacuum dried at 120 ${ }^{\circ} \mathrm{C}$ (for PVDF binder) and $80{ }^{\circ} \mathrm{C}$ (for $\mathrm{CMC}$ binder) overnight. The electrodes were cut into disks, and each disk was loaded with $1 \mathrm{mg} . \mathrm{cm}^{-2}$ active materials, $\sim 0.5 \mathrm{mg}$ of active materials. The cells were fabricated in an argon-filled glove box maintained at less than $0.1 \mathrm{ppm} \mathrm{O}_{2}$ and $\mathrm{H}_{2} \mathrm{O}$ and tested as anodes for LIBs. The NS-RP hybrid electrode was used as the working electrode with Li foil as reference/counter electrode separated by Celgard, soaked in a few drops of $1 \mathrm{M} \mathrm{LiPF}_{6}$ (in 1:1 v/v ethylene carbonate/ diethyl carbonate (EC/DEC)) as electrolyte. All cells were rested overnight to reach equilibrium and exhibited an open circuit voltage of 2.9-3.0 $\mathrm{V}$ against $\mathrm{Li}^{+} / \mathrm{Li}^{0}$. The cells were tested galvanostatically in an advanced multichannel battery tester (Land CT2001A, China) between 0.002 and $3 \mathrm{~V}$ against $\mathrm{Li}^{+} / \mathrm{Li}^{0}$. The galvanostatic intermittent titration technique (GITT) measurements consisted of a series of current pulses applied to the coin cells at a low current density of $100 \mathrm{mAg}^{-1}$ for 20 minutes, each followed by a 90 minute recess to allow full relaxation of lithium diffusion, so as to reach equilibrium potential and to minimize the self-discharge of RP during the test. Cyclic voltammetry $(\mathrm{CV})$ and electrochemical impedance spectroscopy (EIS) were conducted with Biologic VMP3 instruments. CV was conducted with scanning at $0.1 \mathrm{mVs}^{-1}$ between 0.002 and 3.00 V, while EIS was conducted by applying a sine wave $5 \mathrm{mV}$ in amplitude over the frequency range of $0.1 \mathrm{MHz}$ to $10 \mathrm{mHz}$. 


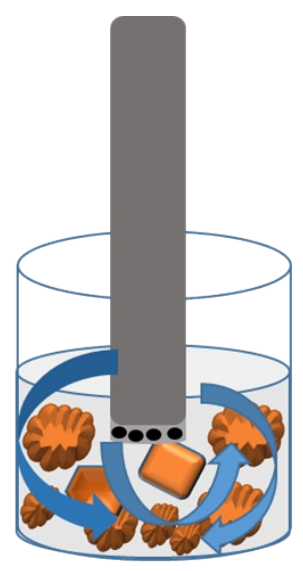

Bulk RP

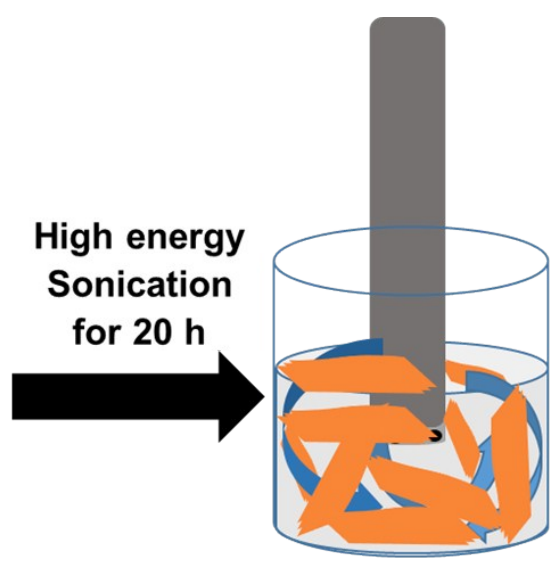

2D layered RP

(NS-RP)

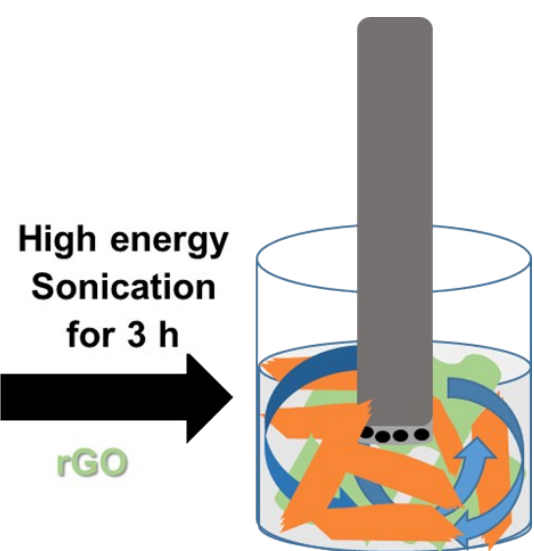

NS-RP@rGO

Hybrid

Scheme 1 Schematic illustration of the synthesis of amorphorus RP films (NS-RP) from bulk RP and synthesis of its hybrid with rGO (NS-RP@rGO).
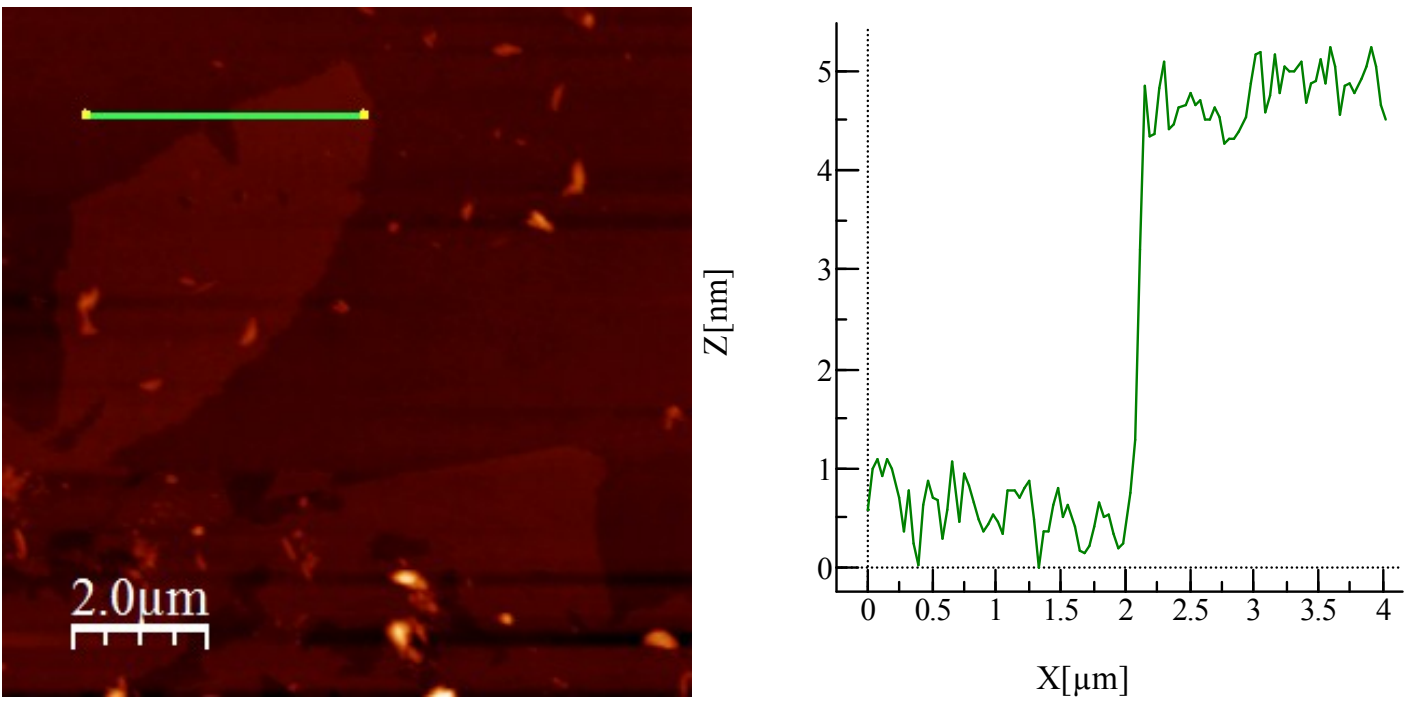
Fig. S0 AFM topography image and depth profile of the NS-RP. The topography show nanosheet morphology of the NS-RP whose thickness is $\sim 4.8 \mathrm{~nm}$.
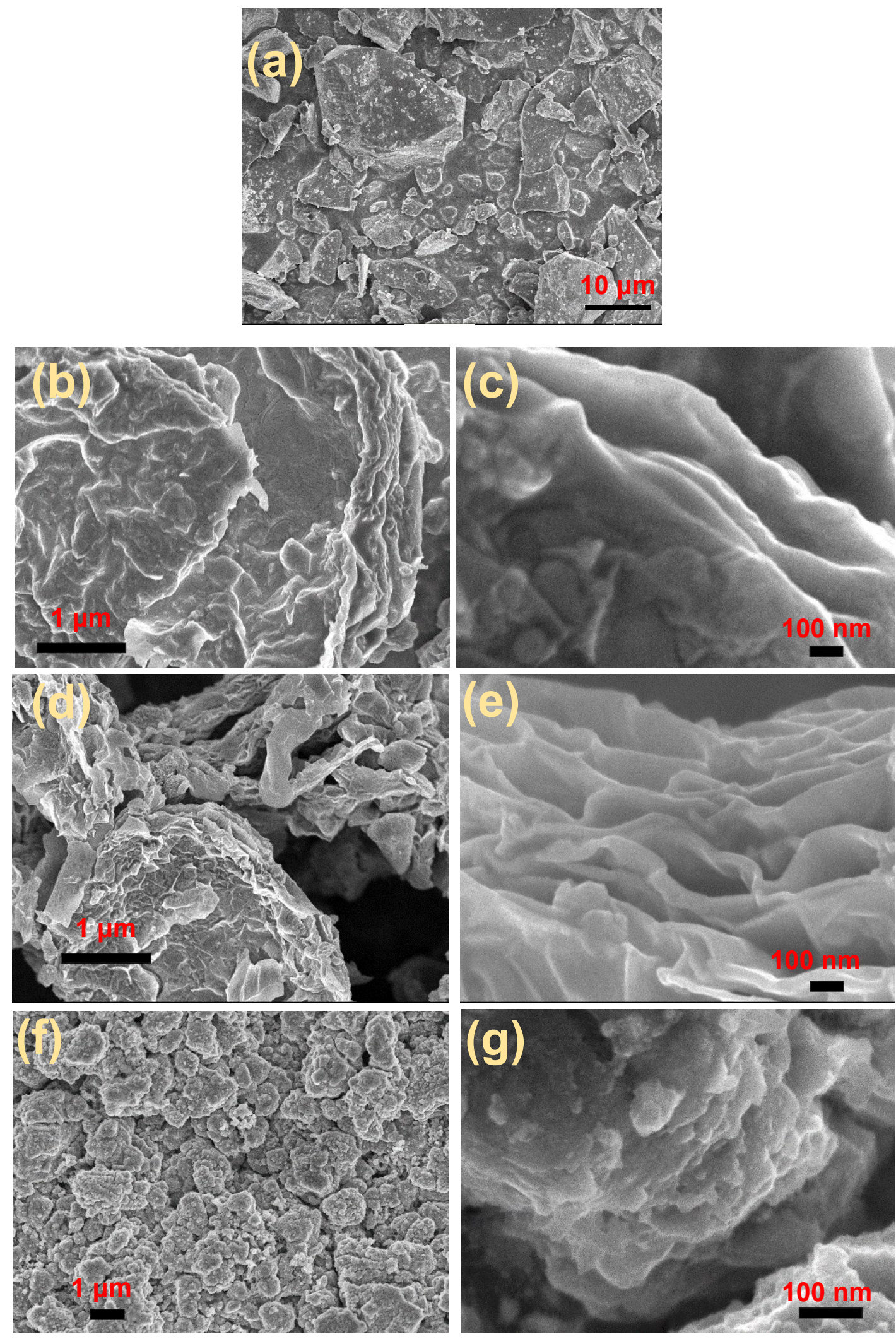
Fig. S1 FESEM images showing the morphology of (a) bulk RP; (b-c) NS-RP@rGO-10; (de) NS-RP@rGO-20; (f-g) NS-RP after 100 cycles
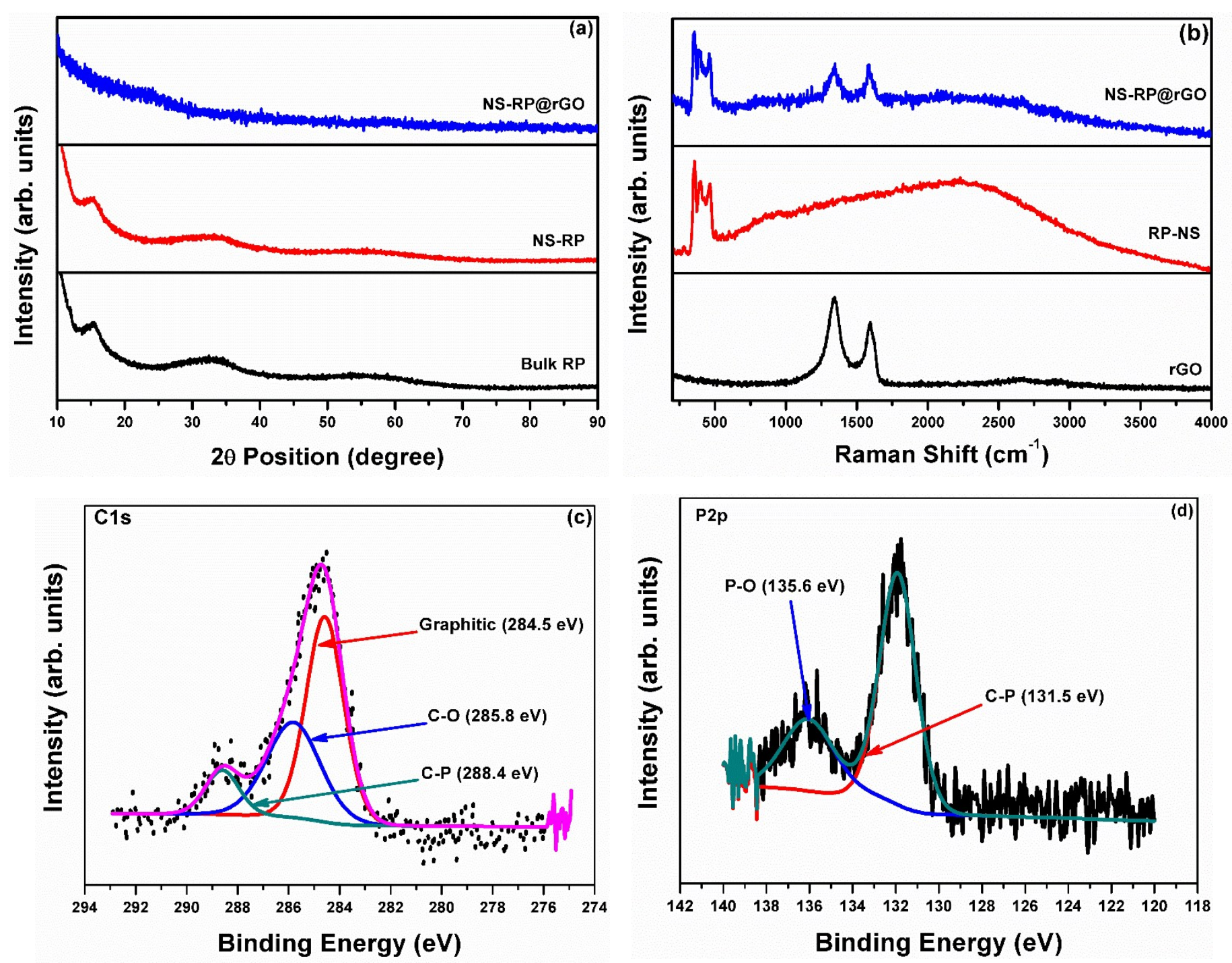
Fig. S2 (a) X ray diffraction patterns and (b) Raman spectra of bulk and amorphous films of red phosphorus (RP) and NS-RP@rGO hybrid composite; high resolution XPS spectra of the (c) C 1s and (d) P 2p regions for the NS-RP@rGO hybrid.

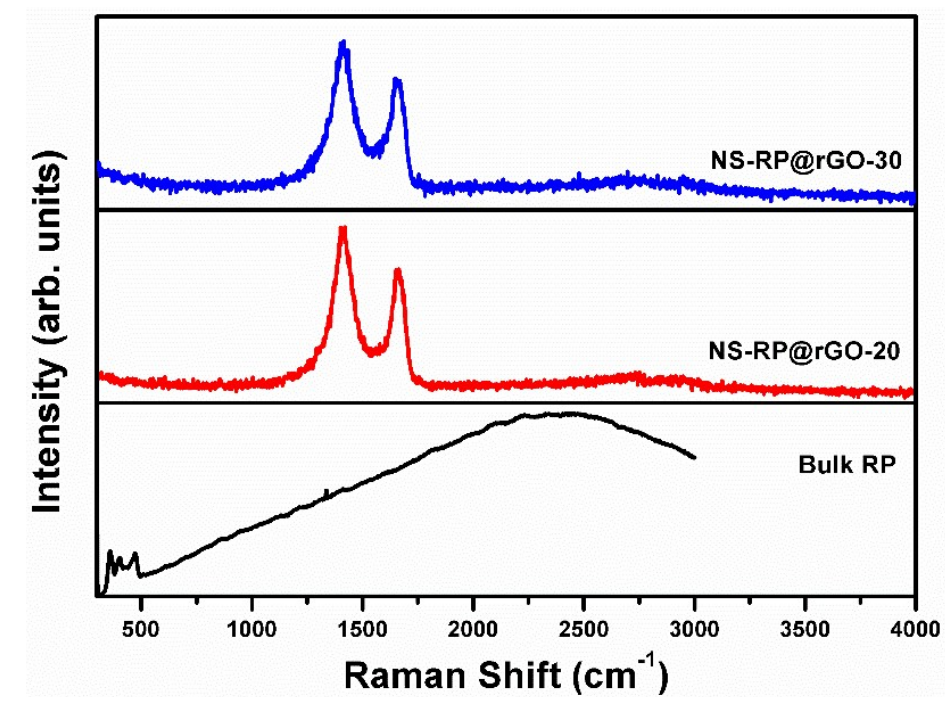

Fig.S3 Raman spectra of bulk RP; NS-RP@rGO-20; and NS-RP@rGO-30 hybrid composites. 

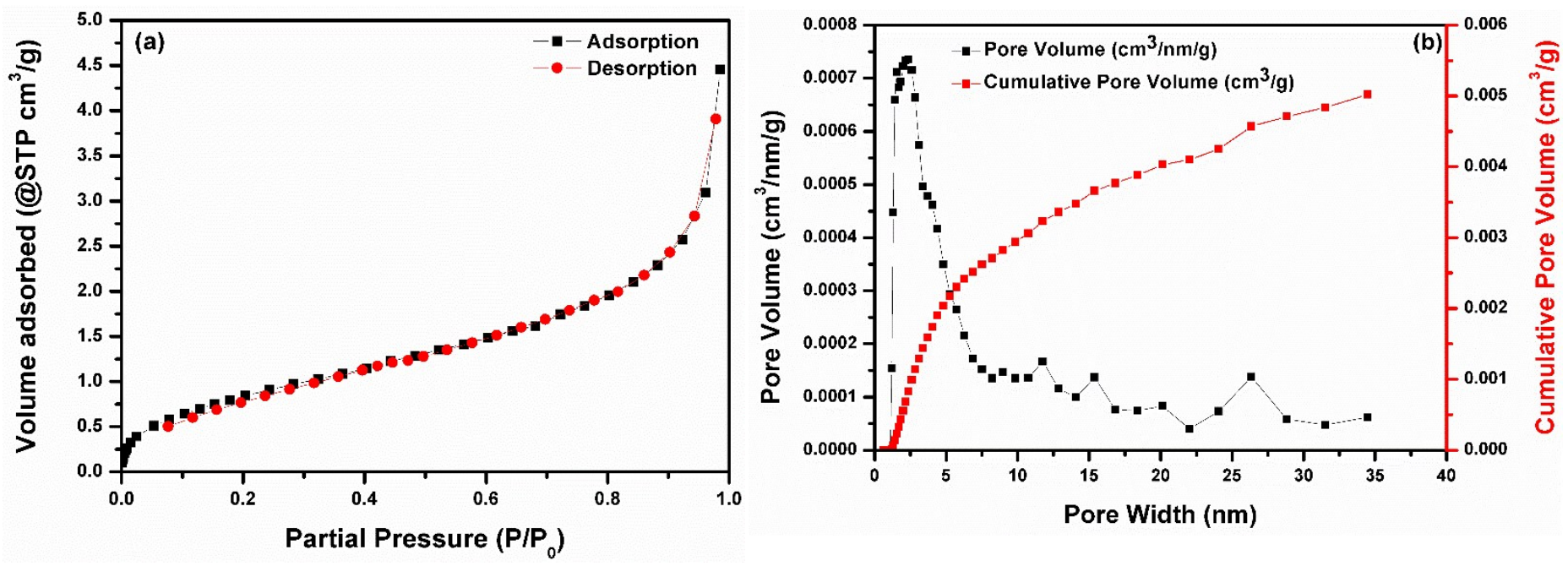
Fig. S4 (a) $\mathrm{N}_{2}$ adsorption-desorption isotherms and Barrett-Joyner-Halenda (BJH) pore size distributions amorphous RP films.
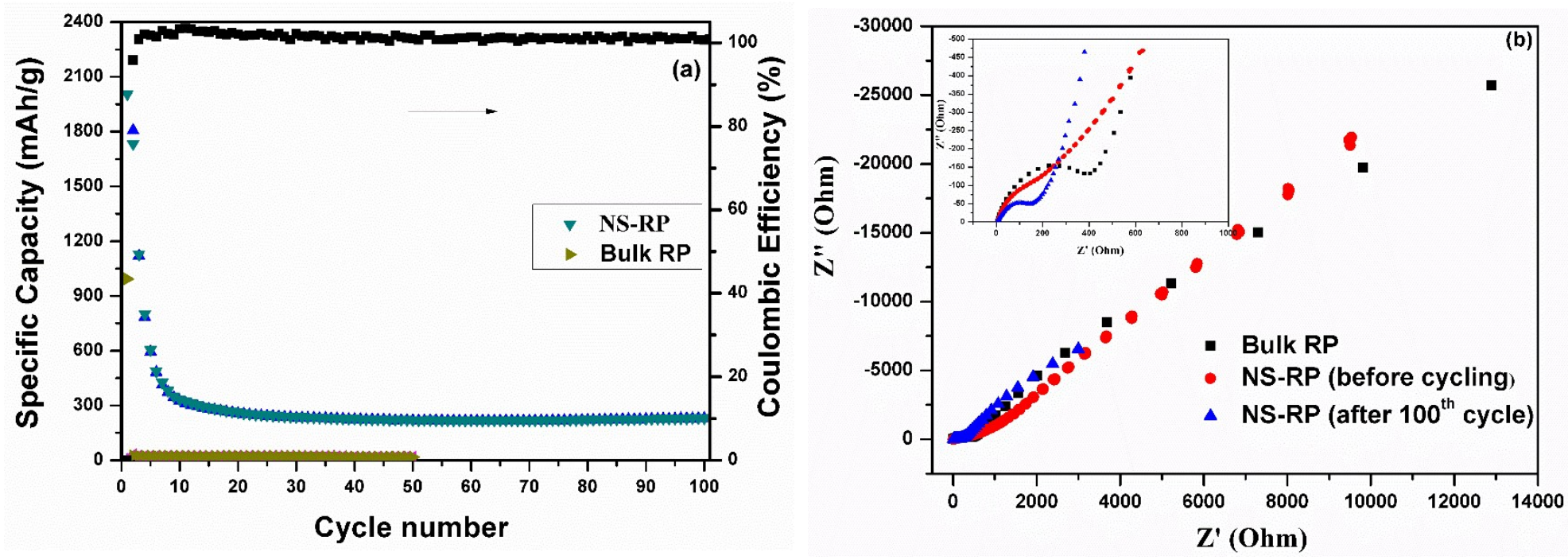
Fig. S5 (a) Long-term cycling stability at $100 \mathrm{mAg}^{-1}$ compared with bulk RP; (b) Electrochemical impedance spectra of samples (inset: enlargement at high frequency)
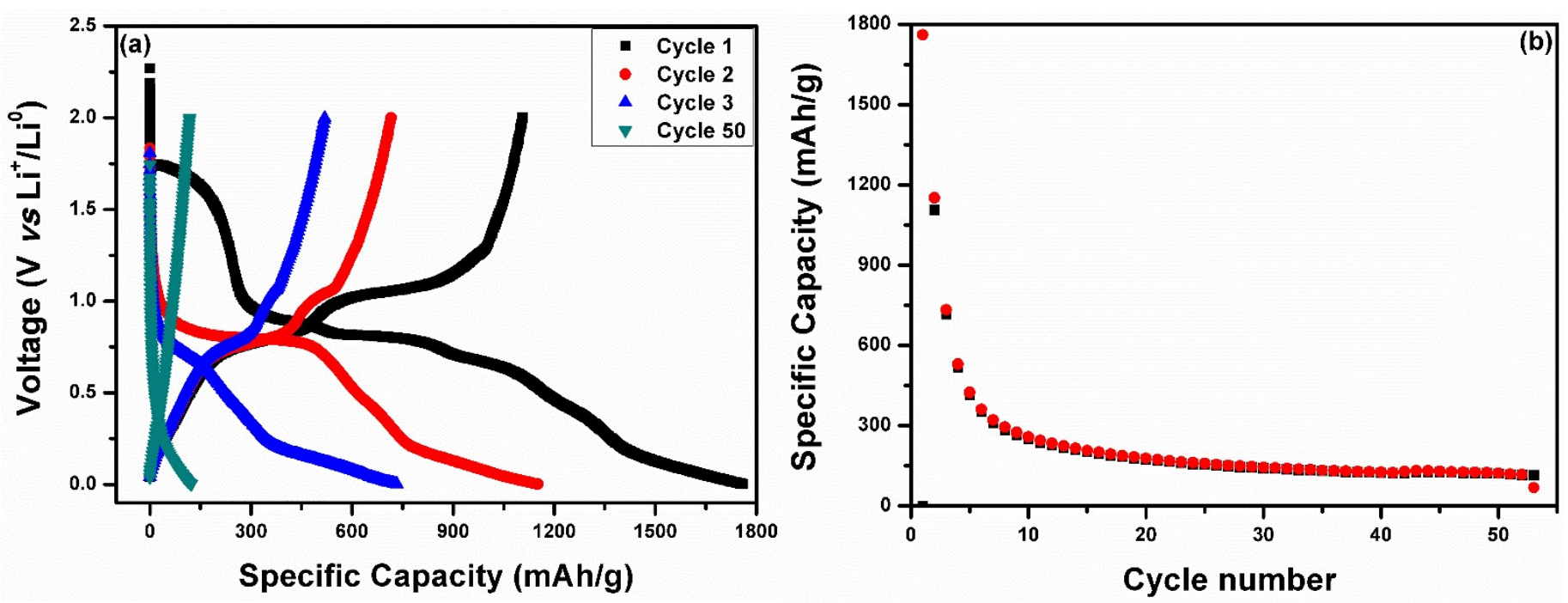
Fig. S6 Electrochemical performance of NS-RP vs. $\mathrm{Li}^{+} / \mathrm{Li}^{0}$ at $50 \mathrm{mAg}^{-1}$ between $0.002-2 \mathrm{~V}$ :

(a) voltage profiles for selected cycles and (b) cycling performance.

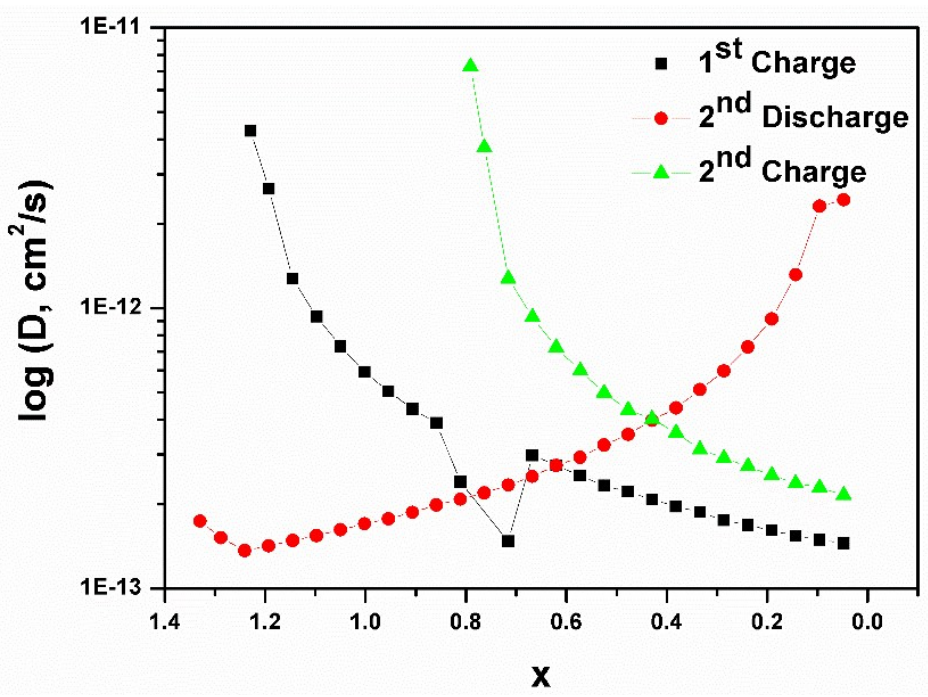

Fig. S7 $\mathrm{Li}^{+}$chemical diffusion coefficient of NS-RP determined by GITT during the chargedischarge process

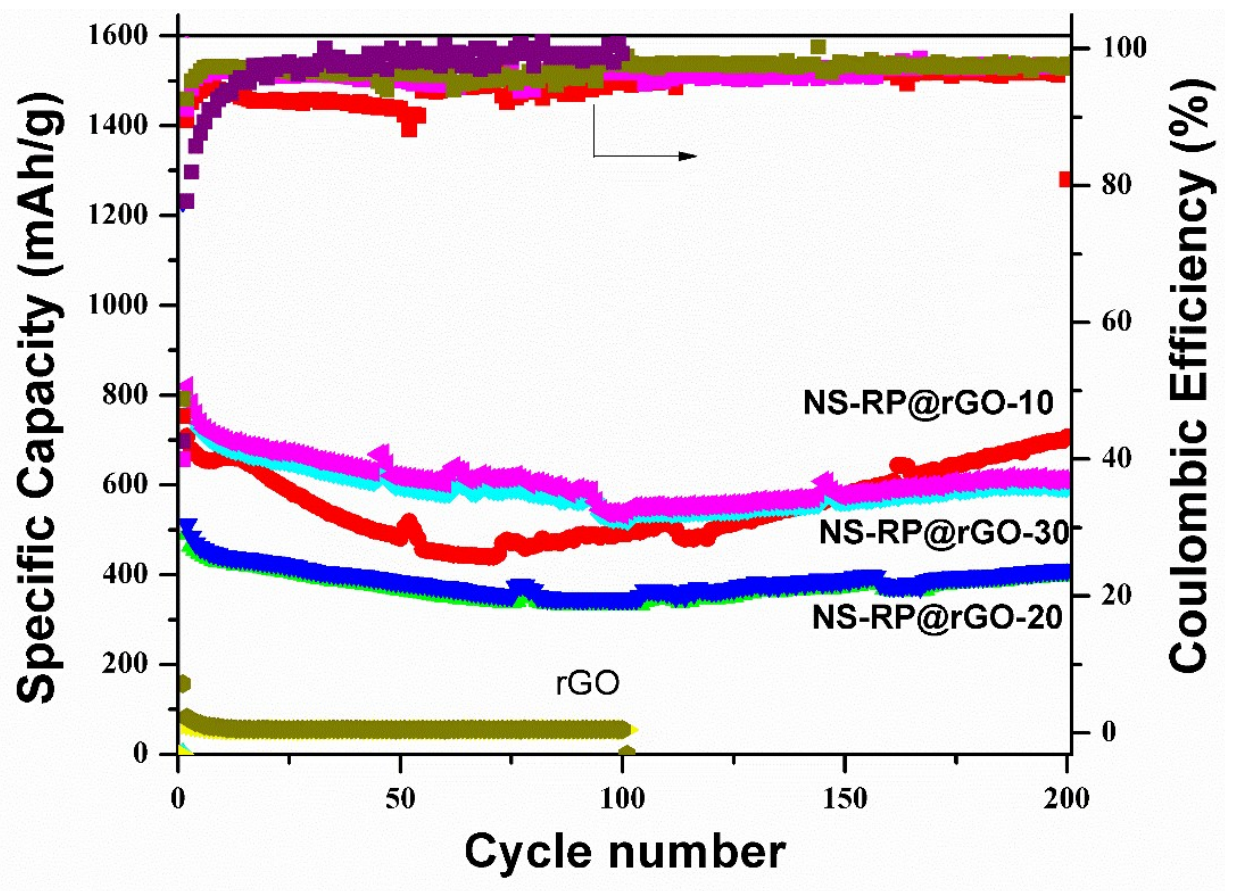


Fig. S8 Long-term cycling performance of NS-RP@rGO composites at $50 \mathrm{mAg}^{-1}$. 